\title{
Assessment of Rogowski Coils for Measurement of Full Discharges in Power Transformers ${ }^{\dagger}$
}

\author{
Rudolf Ribeiro Riehl $* \neq(\mathbb{0}$, Bruno Albuquerque de Castro $\ddagger(\mathbb{0}$, José Renato Castro Pompéia Fraga $\ddagger(\mathbb{C}$,

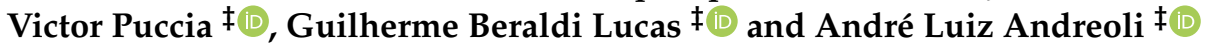

check for

updates

Citation: Riehl, R.R.; de Castro, B.A.; Fraga, J.R.C.P.; Puccia, V.; Lucas, G.B.; Andreoli, A.L. Assessment of Rogowski Coils for Measurement of Full Discharges in Power Transformers. Eng. Proc. 2021, 10, 16. https:// doi.org/10.3390/ecsa-8-11309

Academic Editor: Stefano Mariani

Published: 1 November 2021

Publisher's Note: MDPI stays neutral with regard to jurisdictional claims in published maps and institutional affiliations.

Copyright: (c) 2021 by the authors. Licensee MDPI, Basel, Switzerland. This article is an open access article distributed under the terms and conditions of the Creative Commons Attribution (CC BY) license (https:/ / creativecommons.org/licenses/by/ $4.0 /)$.
Department of Electrical Engineering, School of Engineering, São Paulo State University (UNESP), Bauru 17033-360, SP, Brazil; bruno.castro@unesp.br (B.A.d.C.); jose-renato.fraga@unesp.br (J.R.C.P.F.); victor.puccia@unesp.br (V.P.); guilherme.beraldi@unesp.br (G.B.L.); andre.andreoli@unesp.br (A.L.A.)

* Correspondence: rudolf.riehl@unesp.br

† Presented at the 8th International Electronic Conference on Sensors and Applications, 1-15 November 2021; Available online: https:/ / ecsa-8.sciforum.net.

$\ddagger$ These authors contributed equally to this work.

\begin{abstract}
Science and industry have sought to develop systems aiming to avoid total failures in power transformers since these machines can be working under overloads, moisture, mechanical and thermal stresses, among others. These non-conformities can promote the degradation of the insulation system and lead the transformer to total failure. In the incipient stages of these faults, it is common to detect Full Discharges (FDs), which are short circuits between degraded coils. Therefore, several techniques were developed to perform FD diagnosis using UHF, acoustics, and current sensors. In this scenario, this article presents a mathematical model for Rogowski coils and compares two different types of cores: Ferrite and Teflon. For this purpose, FDs were induced in an oil-filled transformer. The sensitivity and frequency response of the Rogowski coils were compared. This analysis was achieved using the Power Spectrum Density (PSD) and the energy of the acquired signals. Additionally, the Short-Time Fourier Transform (STFT) was applied to detect repetitive discharges. The results indicated that the Ferrite core increases the sensitivity by 50 times in the frequency band between 0 and $1 \mathrm{MHz}$. However, the Teflon core showed higher sensitivity between 5 and $10 \mathrm{MHz}$.
\end{abstract}

Keywords: partial discharges; bushing; insulation systems; infrared sensors; monitoring systems

\section{Introduction}

The incidence of discharges in power transformers can be indicative of the deterioration of the machine insulation system. These non-conformities can lead the transformer to total failure. They usually appear when the device operates under overload, moisture, and mechanical and thermal stresses [1,2].

Partial discharges (PDs) are low-energy ionization processes that occur due to a local field concentration in a dielectric material [3]. On the other hand, full discharges (FDs) perform the complete disruption of the dielectric and can occur permanently or in random periods [4-6]. PDs and FDs are characterized as electric non-conformities that emit UV radiation, current pulses, and acoustic and electromagnetic waves, causing a progressive deterioration of the insulation components. According to Murugan and Ramasamy (2019), the failures of a transformer's windings are commonly caused by short circuits due to internal overheating, conductor tilting, conductor bending, clamping system failure, axial instability, and deformations by careless transformer transportation [4]. All these mechanical stresses can impair the wire insulation and lead the transformer to FDs.

Therefore, several techniques were developed to perform discharge diagnoses such as the UHF approach [7], acoustic analysis [8], optic acoustics technology [9], etc. 
Among these previous methods, one of the most promising discharge detection technique is the analysis of the transformer's current signals [10], which can allow the identification of incipient discharges. In this scenario, several types of current sensors have been developed to perform discharge identification. For example, the sensitivity of the Inductive Loop Sensor was studied by [11]. The authors proposed a current sensor as a single turn and assessed its sensitivity for partial discharges. High-Frequency Current Transform (HFCT) was used in [12] to estimate the charge emitted by discharges. A HallEffect-based sensor was applied to assess the evolution of partial discharges by the current patterns in [13]. One of the most traditional topologies is the Rogowski coils (RC), which are widely applied in the industry to perform current measurements [14]. This type of sensor has a toroidal core wound by wires being the target of several researches.

Moreno et al. (2017) [15] proposed a study on the self-integration of a Rogowski coil to assess current pulses producing sources of partial discharges. Hussain et al. (2020) perform a comparative analysis between a Rogowski coil, high-frequency E-field sensors, and loop antenna to monitor the internal and surface discharges in air-insulated medium-voltage switchgears [16]. Waldi et al. (2020) presented a comparison of different Rogowski coils' geometries to assess their capabilities for discharge detection [17]. The effect of frequency on the linearity of double and single layer coils was studied by [18].

Although all of the mentioned works applied RCs as sensors of monitoring systems, the need for the development of different RCs with different types of cores is crucial to expand the applicability of current analysis. In addition, the development of signal processing analysis to assess the repetition rate of the flaw can improve the maintenance planning, since the increase in the rate can be an indicative of the beginning of a complete failure.

Therefore, this article proposes a comparison between two different types of cores for Rogowski coils: Ferrite and Teflon. Additionally, the mathematical model of the coils was presented, and their electrical parameters were calculated. In experimental tests, full discharges were induced in an oil-filled transformer, and the current signals produced by the Rogowski coils were compared using Power Spectrum Density (PSD) [2]. The Short-Time Fourier Transform (STFT) [6] was applied to detect repetitive discharges. The results indicated that the Ferrite core demonstrates high sensitivity in the frequency band between 0 and $1 \mathrm{MHz}$. Nevertheless, the Teflon core showed higher sensitivity between $5 \mathrm{MHz}$ and $10 \mathrm{MHz}$, which can be a promising alternative to noisy environments since narrow bands can avoid interference.

The outline of this manuscript is as follows: Section 2 presents the mathematical model of Rogowski coils. The experimental setup is described in Section 3, and then, in Section 4, the results are presented and discussed. Section 5 reports the conclusions of this article.

\section{Mathematical Model}

As previous mentioned, RCs are widely applied in industry to perform current measurements, and their construction is based on a toroidal core wound by wires. According to [19-21], a self-integration Rugoski coil can be developed as presented in Figure 1a. Figure $1 \mathrm{~b}$ defines the dimensions abbreviations of the toroidal structure. The equivalent circuit of the Rogowsky coil is characterized as a transformer in which the primary winding is the monitored cable, and the secondary winding is the sensor. The secondary winding is modeled by an RLC (resistive, inductive, and capacitive) circuit. To perform the measurement of the pulses produced by PD activity, a load resistor needs to be coupled in the output of the sensor, as observed in Figure 1c.

For this work, the dimensions of the two sensors were chosen to compare two toroid architectures with the same number of turns but with different core materials (Ferrite and Teflon). Table 1 shows the values of measured dimensions of the two types of cores. 


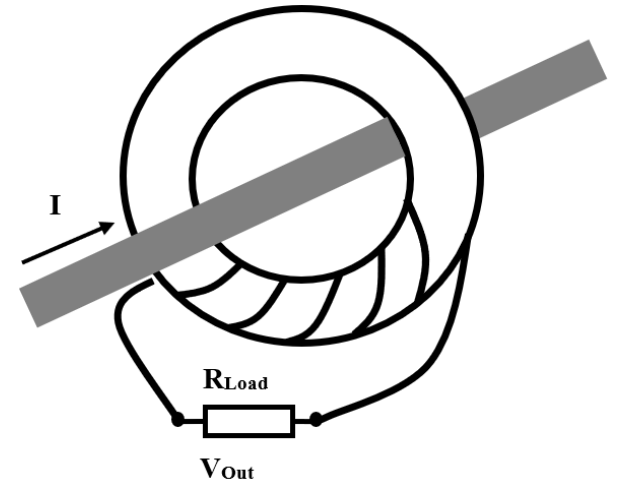

(a)

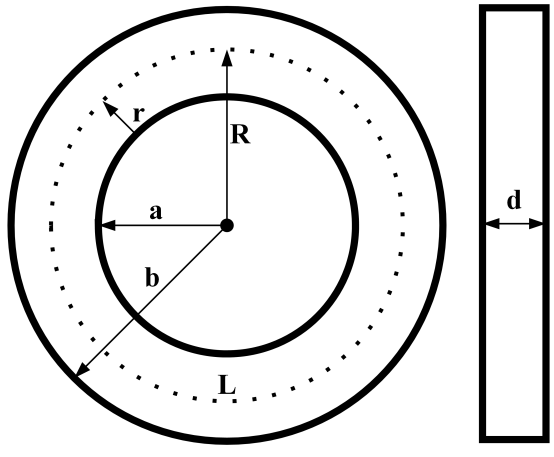

(b)

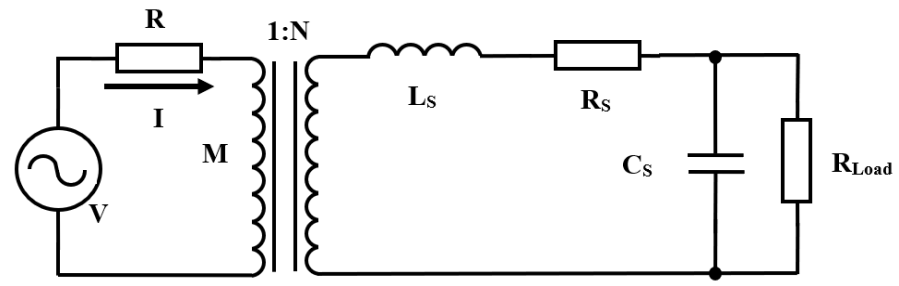

(c)

Figure 1. (a) Coil architecture, (b) Toroid dimensions, and (c) Equivalent circuit.

Table 1. Dimension values.

\begin{tabular}{ccc}
\hline Dimensions & Ferrite & Teflon \\
\hline Turns (N) & 50 & 50 \\
Toroid average length (L) & $78.9 \mathrm{~mm}$ & $86.2 \mathrm{~mm}$ \\
Toroid thickness (d) & $12.46 \mathrm{~mm}$ & $11.15 \mathrm{~mm}$ \\
Inner radius (a) & $18.75 \mathrm{~mm}$ & $19.33 \mathrm{~mm}$ \\
Outer radius (b) & $31.45 \mathrm{~mm}$ & $35.36 \mathrm{~mm}$ \\
Toroid average radius (R) & $25.1 \mathrm{~mm}$ & $27.35 \mathrm{~mm}$ \\
Toroide average width (r) & $6.35 \mathrm{~mm}$ & $9.02 \mathrm{~mm}$ \\
\hline
\end{tabular}

The electrical parameters seen in Figure 1c can be calculated by [19-21]:

$$
\begin{gathered}
L_{S}=\frac{\mu}{2 \pi} \cdot N^{2} \cdot d \cdot \log \left(\frac{b}{a}\right) \\
M=\frac{\mu}{2 \pi} \cdot N \cdot d \cdot \log \left(\frac{b}{a}\right) \\
R_{S}=\rho \cdot \frac{4 \cdot L_{w}}{\pi \cdot D^{2}} \\
C_{S}=\frac{4 \cdot \pi \cdot \epsilon_{0} \cdot R}{\log \left(\frac{R}{r}\right)}
\end{gathered}
$$

where $\mu=\mu_{0} \mu_{r}, \mu_{0}$ is the air permeability, $\mu_{r}$ is the relative permeability of the material (Teflon $=1$, Ferrite $=2500), \epsilon_{0}$ is the air dielectric constant, $\rho$ is the copper resistivity, $L_{w}$ is the total wire length, and $D$ is the wire diameter. Additionally, the output $V_{\text {out }}$ across resistor $R_{\text {load }}$ can be achieved using:

$$
V_{\text {out }}=\frac{R_{\text {load }}}{L_{d}} \cdot M \cdot I
$$


where $L_{d}$ is $L_{s} / L_{w}$. Hence, the current $I$ can be measured by reading the voltage $V_{\text {out }}$ across the load resistor.

The value chosen for $R_{\text {load }}$ was $50 \Omega$. In addition, the wire diameter (D) is $0.40386 \mathrm{~mm}$ and the wire length $\left(L_{w}\right)$ is $2 \mathrm{~m}$ for both coils. Finally, using the previous information, the values of the electrical parameters were calculated (Table 2).

Table 2. Dimension values.

\begin{tabular}{ccc}
\hline Parameter & Teflon & Ferrite \\
\hline$L_{s}$ & $1.4 \mu \mathrm{H}$ & $3.65 \mathrm{mH}$ \\
$M$ & $28 \mathrm{nH}$ & $73.1 \mu \mathrm{H}$ \\
$R_{s}$ & $0.268 \Omega$ & $0.268 \Omega$ \\
$C_{s}$ & $4.68 \mathrm{pF}$ & $6.32 \mathrm{pF}$ \\
\hline
\end{tabular}

\section{Materials and Methods}

In order to assess the sensitivity of the Rogowski coils to FD detection, several tests were carried out in a power transformer $(30 \mathrm{kVA}, 13.8 \mathrm{k} / 220 \mathrm{~V})$. An electrode with a $5 \mathrm{~mm}$ gap was immersed in the transformer oil (Figure 2a) to generate FDs. A high voltage source (General Electric ${ }^{\circledR} 0-40 \mathrm{kVac}$ ) was applied to the electrode, and it was observed that FD activity started at $3.5 \mathrm{kV}$.

The transformer was grounded, and the supply cables were involved by the two coils (Figure 2b). An oscilloscope (Yokogawa ${ }^{\circledR} D L 850(100 \mathrm{MHz})$ ) was used to acquire the voltage across the resistor $R_{\text {load }}(50 \mathrm{ohms})$. The sampling frequency was set to $50 \mathrm{MS} / \mathrm{s}$. The signals were processed by Matlab ${ }$ software using the Short-time Fourier Transform and the Power Spectrum Density function. Both of these techniques were successfully applied to fault detection in electrical machines in previous works [2,22].

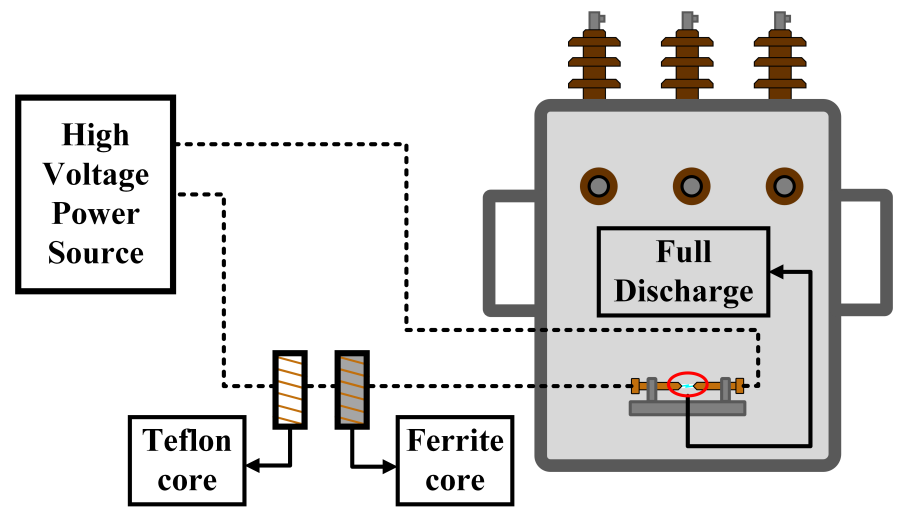

(a)

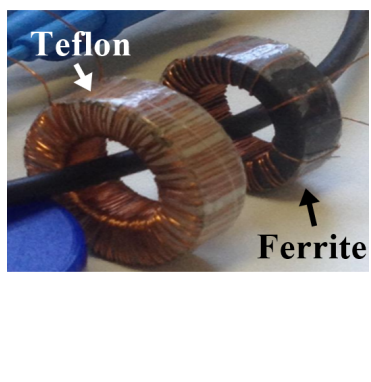

(b)

Figure 2. Test bench for PD generation (a) and Rogowski Coils (b).

\section{Results and Discussion}

The full discharge current signals provided by the Teflon and Ferrite coils are presented in Figure 3. Since the measures were taken simultaneously, five full discharge peaks can be observed for both core materials. However, by comparing Figure $3 \mathrm{a}, \mathrm{b}$, it is clear that each coil type presents different frequency and time responses. 


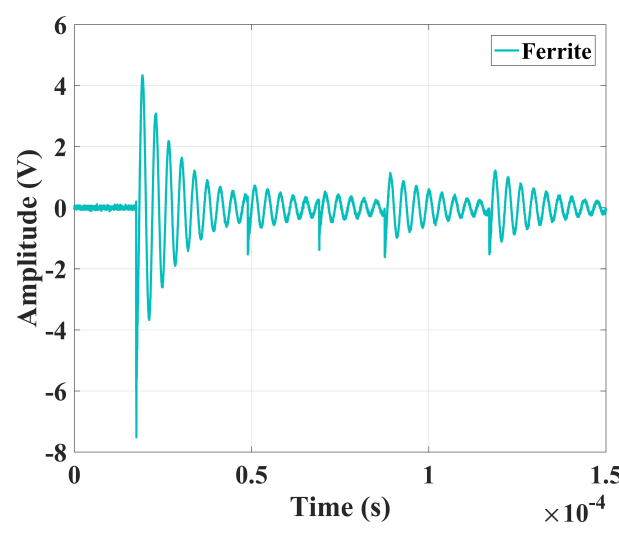

(a)

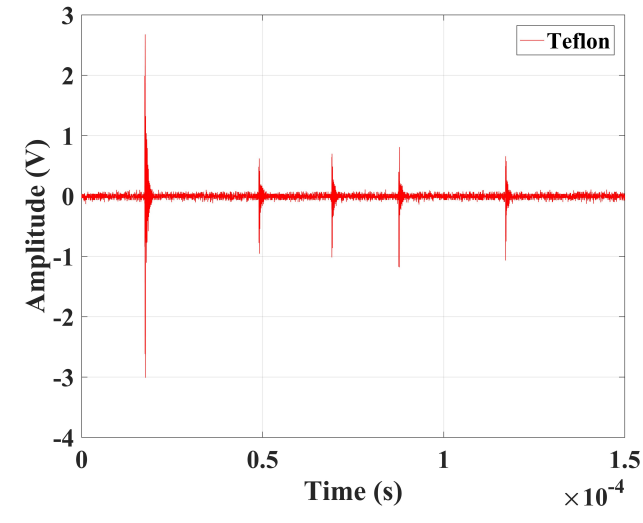

(b)

Figure 3. PD signals in time domain for Ferrite (a) and Teflon (b) cores.

Therefore, the Fourier Transform was applied to the discharge signals to achieve the PSD for both sensors (Figure 4). In addition, considering the full discharges as impulsive current signals in the time domain, these results describe the frequency response of the sensors. The result reveals that the Ferrite coil has a higher power density in the $0-1 \mathrm{MHz}$ range. On the other hand, the Teflon coil presented a higher power density between 5 and $10 \mathrm{MHz}$.

To further investigate the application of the sensors for full discharge detection, the STFT was applied to the current signals (Figure 5). This technique allowed the analysis of the frequency pattern of the currents over the entire acquisition period. In Figure 5a, all five discharge peaks could be identified by high power values using the Ferrite coil. In the same way, the faults were also detected by using the Teflon coil in Figure 5b. Although the power spectrum density can characterize the occurrence of FD, this technique cannot assess the recurrence of the failure such as STFT.

The previous results indicate that both sensors are capable of assessing the full discharges in power transformers. However, the Teflon coil can be pointed out as a better alternative for fault detection for two reasons:

1. In industrial scenarios, electromagnetic noise is generally restricted to a maximum of hundreds of kilohertz. However, the frequency response of the Teflon coil is limited to 5 to $10 \mathrm{MHz}$. Therefore, this device avoids measurement errors due to high noise industrial scenarios. On the other hand, the Ferrite coil proved to be more sensitive to these noises since it presented a high PSD for lower frequencies.

2. The production cost of the Teflon coil is financially advantageous compared to the Ferrite coil due to the composition of the core.

The results presented are focused on a comparative analysis of two material coils and in the identification of the recurrence of discharges in the transformer, which can be indicative of the start of a total failure. Therefore, this work differs from the literature, since the major part of the research is focused on the separation of different PD types or the improvement of the sensitivity by using a self-integration such as that observed in [15]. In addition, different Rogowski coil geometries to assess their capabilities to discharge detection were studied by [17]. Nevertheless, none of them try to assess the sensitivity of the RGs by the discharges' recurrence or study the influence of the type of the coil. 


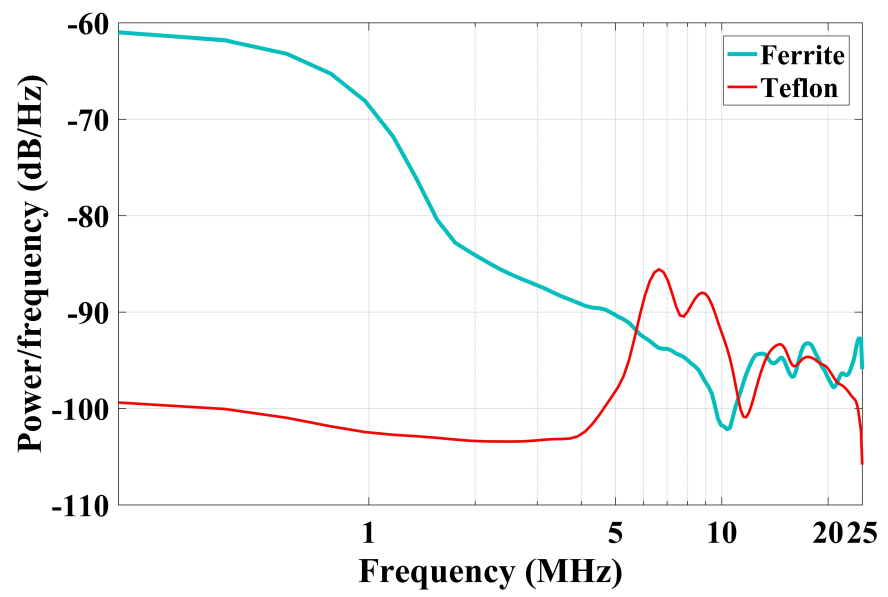

Figure 4. Power spectrum densities for Rogowski coils based on Ferrite and Teflon.

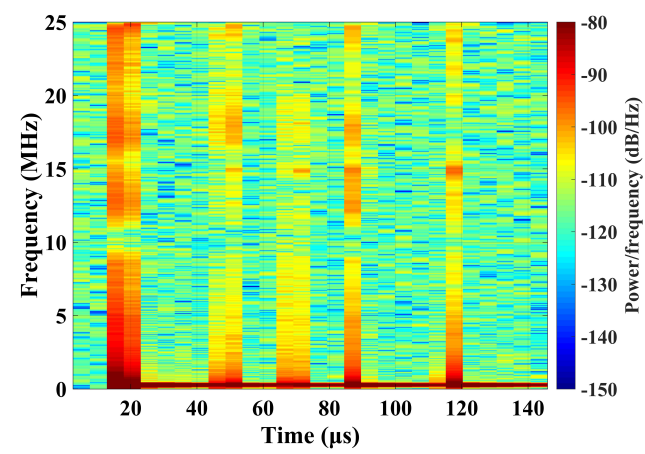

(a)

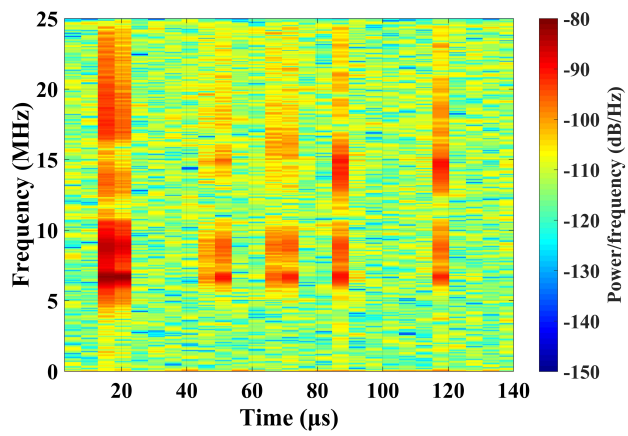

(b)

Figure 5. STFT for (a) Ferrite and (b) Teflon cores.

\section{Conclusions}

Full discharge detection is crucial for power transformer maintenance plans. Hence, this article presents a comparison between two topologies of Rogowski coils for discharge identification. The mathematical model of the sensor was presented, and the sensitivity of Ferrite and Teflon coils was assessed by PSD and STFT. The results indicate that although the two topologies provided promising results for fault evaluation, it can be concluded that the Teflon coil has more advantageous features and better noise immunity for industrial applications due to its narrow response band. In addition, Teflon has a low cost in relation to Ferrite, being an alternative to expand nondestructive testings in power transformers. Future works can evaluate other topologies and the capability of these sensors to perform separation of discharge types.

Author Contributions: Methodology, B.A.d.C. and V.P.; formal analysis R.R.R.; software, B.A.d.C. and V.P.; validation, J.R.C.P.F. and G.B.L.; writing, J.R.C.P.F. and G.B.L.; writing-review and editing, B.A.d.C. and A.L.A.; resources, A.L.A.; supervision and project administration, R.R.R. All authors have read and agreed to the published version of the manuscript.

Funding: This research received no external funding.

Institutional Review Board Statement: Not applicable.

Informed Consent Statement: Not applicable.

Data Availability Statement: The data presented in this study are available upon reasonable request.

Conflicts of Interest: The authors declare no conflict of interest. 


\section{References}

1. Hussain, M.R.; Refaat, S.S.; Abu-Rub, H. Overview and Partial Discharge Analysis of Power Transformers: A Literature Review. IEEE Access 2021, 9, 64587-64605. [CrossRef]

2. De Castro, B.A.; de Melo Brunini, D.; Baptista, F.G.; Andreoli, A.L.; Ulson, J.A.C. Assessment of macro fiber composite sensors for measurement of acoustic partial discharge signals in power transformers. IEEE Sens. J. 2017, 17, 6090-6099. [CrossRef]

3. International Electrotechnical Commission. High-Voltage Test Techniques: Partial Discharge Measurements; IEC-60270; IEC: Geneva, Switzerland, 2000; pp. 13-31.

4. Murugan, R.; Ramasamy, R. Understanding the power transformer component failures for health index-based maintenance planning in electric utilities. Eng. Fail. Anal. 2019, 96, 274-288. [CrossRef]

5. Sikorski, W. Development of acoustic emission sensor optimized for partial discharge monitoring in power transformers. Sensors 2019, 19, 1865. [CrossRef] [PubMed]

6. Binotto, A.; Castro, B.A.d.; Santos, V.V.d.; Rey, J.A.A.; Andreoli, A.L. A Comparison between piezoelectric sensors applied to multiple partial discharge detection by advanced signal processing analysis. Eng. Proc. 2020, 2, 55.

7. Beura, C.P.; Beltle, M.; Tenbohlen, S. Study of the Influence of Winding and Sensor Design on Ultra-High Frequency Partial Discharge Signals in Power Transformers. Sensors 2020, 20, 5113. [CrossRef] [PubMed]

8. dos Santos, V.V.; de Castro, B.A.; Binotto, A.; Rey, J.A.A.; Lucas, G.B.; Andreoli, A.L. An application of wavelet analysis to assess partial discharge evolution by acoustic emission sensor. In Proceedings of the 7th Electronic Conference on Sensors and Applications, online, 15 November 2020; Volume 15, p. 30.

9. Li, H.; Bu, J.; Li, W.; Lv, J.; Wang, X.; Hu, K.; Yu, Y. Fiber optic Fabry-Perot sensor that can amplify ultrasonic wave for an enhanced partial discharge detection. Sci. Rep. 2021, 11, 1-6. [CrossRef] [PubMed]

10. Ardila-Rey, J.A.; Montaña, J.; De Castro, B.A.; Schurch, R.; Covolan Ulson, J.A.; Muhammad-Sukki, F.; Bani, N.A. A comparison of inductive sensors in the characterization of partial discharges and electrical noise using the chromatic technique. Sensors 2018, 18, 1021. [CrossRef] [PubMed]

11. Ardila-Rey, J.A.; Barrueto, A.; Zerene, A.; Castro, B.A.d.; Ulson, J.A.C.; Mas'ud, A.A.; Valdivia, P. Behavior of an inductive loop sensor in the measurement of partial discharge pulses with variations in its separation from the primary conductor. Sensors 2018, 18, 2324. [CrossRef] [PubMed]

12. Rodrigo-Mor, A.; Muñoz, F.A.; Castro-Heredia, L.C. Principles of charge estimation methods using high-frequency current transformer sensors in partial discharge measurements. Sensors 2020, 20, 2520. [CrossRef] [PubMed]

13. Binotto, A.; de Castro, B.A.; Ardila-Rey, J.A.; Andreoli, A.L. Partial Discharge Detection of Transformer Bushing Based on Acoustic Emission and Current Analysis. In Proceedings of the 2021 IEEE XXVIII International Conference on Electronics, Electrical Engineering and Computing (INTERCON), Lima, Peru, 5-7 August 2021; pp. 1-4.

14. Shi, Y.; Xin, Z.; Loh, P.C.; Blaabjerg, F. A Review of Traditional Helical to Recent Miniaturized Printed Circuit Board Rogowski Coils for Power-Electronic Applications. IEEE Trans. Power Electron. 2020, 35, 12207-12222. [CrossRef]

15. Moreno, M.V.R.; Robles, G.; Albarracín, R.; Rey, J.A.; Tarifa, J.M.M. Study on the self-integration of a Rogowski coil used in the measurement of partial discharges pulses. Electr. Eng. 2017, 99, 817-826. [CrossRef]

16. Hussain, G.A.; Zaher, A.A.; Hummes, D.; Safdar, M.; Lehtonen, M. Hybrid sensing of internal and surface partial discharges in air-insulated medium voltage switchgear. Energies 2020, 13, 1738. [CrossRef]

17. Waldi, E.P.; Lestari, A.I.; Fernandez, R.; Mulyadi, S.; Murakami, Y.; Hozumi, N. Rogowski coil sensor in the digitization process to detect partial discharge. Telkomnika 2020, 18, 1062-1071. [CrossRef]

18. Liu, X.; Huang, H.; Dai, Y. Effect of Frequency on the Linearity of Double-Layer and Single-Layer Rogowski Coils. IEEE Sens. J. 2020, 20, 9910-9918. [CrossRef]

19. Argüeso, M.; Robles, G.; Sanz, J. Implementation of a Rogowski coil for the measurement of partial discharges. Rev. Sci. Instrum. 2005, 76, 065107. [CrossRef]

20. Radun, A. An alternative low-cost current-sensing scheme for high-current power electronics circuits. IEEE Trans. Ind. Electron. 1995, 42, 78-84. [CrossRef]

21. Zhang, Q.; Zhu, J.; Jia, J.; Tao, F.; Yang, L. Design of a current transducer with a magnetic core for use in measurements of nanosecond current pulses. Meas. Sci. Technol. 2006, 17, 895-900. [CrossRef]

22. Carvalho, L.; Lucas, G.; Rocha, M.; Fraga, C.; Andreoli, A. Undervoltage Identification in Three Phase Induction Motor Using Low-Cost Piezoelectric Sensors and STFT Technique. Proceedings 2019, 42, 72. [CrossRef] 